\title{
How Impulsivity is Related to Intelligence and Academic Achievement
}

\author{
Andreu Vigil-Colet and Fabia Morales-Vives \\ Universidad Rovira y Virgili
}

This study investigated the relationships between impulsivity, intelligence, and academic failure in a sample of 241 secondary school students who completed Thurstone's (1938) Primary Mental Abilities (PMA) test and Dickman's (1990) and Barratt's (1985) impulsivity questionnaires (DII and BIS-10, respectively). Results show an inverse relationship between impulsivity and intelligence, specific to the scales with higher loadings on crystallized intelligence, and a positive relationship between impulsivity and academic failure. These results indicate that impulsivity is not directly related to intelligence and may act as a moderator variable between individuals' resources and their achievements.

Keywords: impulsivity, intelligence, academic achievement

El presente estudio analiza las relaciones existentes entre impulsividad, inteligencia y fracaso escolar en una muestra de 241 estudiantes de secundaria utilizando el test de Aptitudes Mentales Primarias de Thurstone (1938) y los cuestionarios de Dickman (1990) y Barratt (1985) de impulsividad (DII y BIS-10, respectivamente). Los resultados muestran una relación inversa entre impulsividad e inteligencia que es específica de las escalas que presentan mayor saturación en inteligencia cristalizada así como una relación positiva entre la impulsividad y el fracaso escolar. Estos resultados parecen indicar que la impulsividad no está directamente relacionada con la inteligencia y que esta puede actuar como variable moderadora entre los recursos del individuo y sus logros.

Palabras clave: impulsividad, inteligencia, fracaso escolar

This research was supported by a grant from the Ministerio de Ciencia y Tecnología (SEC2001-3821-C05-C02) with the collaboration of the European Fund for the Development of Regions.

Correspondence should be addressed to Andreu Vigil-Colet, Universidad Rovira y Virgili, Facultad de Ciencias de la Educación y Psicología, Crtra. Valls s/n, 43007 - Tarragona (Spain). E-mail: avc@ fcep.urv.es 
Research on the relationships between major personality dimensions and intelligence has proved that is difficult to obtain consistent and replicable correlations between them and that, at a general level, personality is weakly related to intelligence (Austin, Deary, \& Gibson, 1997; Demetriou, Kyriakides, \& Avraamidou 2003). Furthermore, it seems that the relationships between personality dimensions and intelligence are better established at a crystallized intelligence (Gc) level than at the fluid intelligence (Gf) level (Ashton, Lee, Vernon, \& Lang, 2000; Goff \& Ackerman, 1992; Jensen, 1998).

There are several explanations for the relationships between intelligence and personality. Jensen (1998) proposed that this relationship can be explained by R. B Cattell's investment theory, in the sense that individual differences in achievements are due to the different ways in which individuals "invest" their $g$ resources, because it is at this level that personality may be related to intelligence. This theory also explains why crystallized intelligence is more related to personality than is fluid intelligence, because personality will affect achievements more than ability.

Another possible explanation, which may complement the first, was proposed by Ackermann (Ackerman, 1994; Goff \& Ackerman 1992): Intelligence can be maximal engagement or typical engagement. Ackerman's proposal focuses on the fact that performance in psychometric tests of intelligence reflects an environment in which maximal performance is measured, whereas an individual's academic or occupational performance takes place in a typical performance environment. From this viewpoint, intelligence as typical performance will be more related to crystallized intelligence and will be more affected by personality than intelligence as maximal performance, which is more related to fluid intelligence.

One of the most exhaustive research projects on the relationships between intelligence and personality was carried out by Ackerman and Heggestad (1997), using meta-analysis. They found that two categories of personality traits are positively related to intelligence. The first category is related to Extroversion, whereas the second category refers to intellectually oriented traits such as Openness to Experience, which has frequently been related to crystallized intelligence (Ashton et al., 2000; Bates \& Shieles, 2003). Moreover, other personality traits such as Neuroticism and Psychoticism were negatively related to intelligence. This negative relationship between Neuroticism, Psychoticism, and intelligence has also been reported by other authors such as Eysenck (1994) and Furnham, Forde and Cotter (1998).

Within this framework of the intelligence-personality relationship, one personality dimension that has not been given much consideration is impulsivity. Some results seem to show that there is a slight negative relationship between impulsivity and performance in reasoning (Schweizer, 2002) and between impulsivity and intelligence (Lynam, Moffitt, \& Stouthamer-Loeber, 1993), and that this relationship is greater for verbal IQ. On the other hand, in certain circumstances, impulsivity may be positively related to intelligence. In this respect, Phillips and Rabbitt (1995) proposed that impulsivity is positively correlated with intelligence test scores when the test consists of relatively easy questions that must be answered rapidly. In these conditions, working quickly without checking may be advantageous because this is the strategy that individuals with high impulsivity often use. Impulsive individuals also seem to perform better in intelligence tests under certain manipulations of their arousal level. This result is similar to the improved performance of extroverts when they are tested under high arousal conditions (Bates \& Rock, 2004; Brebner \& Stough, 1995).

In the achievements domain, impulsivity seems to be inversely related to academic achievement, which is often related to intelligence — particularly, crystallized intelligenceand associated with learning disabilities (Fink \& McCown, 1993). Impulsivity seems to act as a moderator variable between intelligence and academic success; for instance, individuals with high impulsivity and high academic ability tend to have lower grades than do individuals with high academic ability and low impulsivity (Helmers, Young, \& Pihl, 1995; Zeidner, 1995). One possible explanation is that individuals with a poor academic performance tend to show an impulsive/careless problem-solving style; they use poorer problem-solving strategies in tasks where the response is not immediately obvious, and give the first answer that comes to mind (Fink \& McCown, 1993). From this viewpoint, authors such as McMurran, Blair, and Egan (2002) have proposed that impulsivity may be an obstacle to learning in the early developmental years.

Another domain that has been explored in relation to the impulsivity-intelligence relationship is that of the effect of cognitive styles on intelligence. From this perspective, individuals with an impulsive style tend to respond quickly, with little reflection or analysis, which leads to poorer performance on intelligence tests. As a consequence, the median correlation between impulsivity style and IQ test scores is -.30. This relationship may be due to the fact that reflectivity is a manifestation of $g$ ability (Jensen, 1981; Messer, 1976; Weijers, Wiesbeck, \& Böning 2001).

In 1990, S. J. Dickman proposed an approach to impulsivity that may be relevant to the relationships between impulsivity and intelligence. He proposed the existence of two types of impulsivity. The first is functional impulsivity, which is related to a tendency to take quick decisions when they are required by the situation for personal gain. The second is dysfunctional impulsivity and is related to speedy and irreflexive decisions, which have negative consequences for the individual. From this theoretical framework, Dickman developed an inventory to discriminate between these factors. Factorial analysis revealed two main factors that were related to functional and dysfunctional impulsivity. This factorial structure has also been found in Dutch (Claes, Vertommen, \& Braspenning, 2000) and Spanish (Chico, Tous, LorenzoSeva, \& Vigil-Colet, 2003) populations. Furthermore, the 
factors that emerged in the versions of Dickman's questionnaire for different languages showed a high degree of congruence.

Dickman (1990) also analyzed the way in which functional and dysfunctional impulsivity were related to an individual's information-processing style. Functional impulsivity was related to a rapid information-processing style, whereas dysfunctional impulsivity was related to the inability to inhibit competing responses (Brunas-Wagstaff, Bergquist, \& Wagstaff, 1994). Lastly, Dickman (1993, 2000) proposed that high and low dysfunctional impulsive individuals differ in their capacity to focus on the source of inputs. From this viewpoint, dysfunctional individuals have difficulty in focusing their attention on the decision-making processes and, as a result, act with little forethought.

Taking into account the characteristics of functional impulsivity, Claes et al. (2000) pointed out that it may be related to intelligence. They paid particular attention to the fact that research into biological models of intelligence has revealed a relationship between speed of information processing and intelligence (Eysenck, 1987; Jensen, 1993). This relationship may imply a relationship between functional impulsivity and intelligence because of the association of functional impulsivity with speedy decisions that are appropriate for the situation.

The aim of the present study is to analyze the relationships between impulsivity and intelligence with two main objectives.

The first objective is to analyze the existence of a negative relationship between impulsivity and both intelligence and academic achievement. If this relationship is found, we expect impulsivity to affect the way that individuals use their resources, which may hinder the learning processes. As a result, impulsivity will be more related to measures of crystallized intelligence and academic failure than to measures of fluid intelligence. The second objective is to assess whether functional impulsivity is related to intelligence, because of its apparent relationship to the speed of processing.

\section{Method}

\section{Participants}

The participants were 241 secondary school students (107 boys and 134 girls) from two state schools in Tarragona and Montblanch, Catalonia, Spain. The participants were between 12 and 17 years old $(M=14.21, S D=1.02)$.

\section{Instruments}

Primary Mental Abilities (Thurstone, 1938). The psychometric measure of intelligence that we administered was the Spanish adaptation of Thurstone's Primary Mental Abilities Thurstone (1938). The subscales of Thurstone's test were: Verbal (PMA-V), Spatial (PMA-S), Numerical (PMA$\mathrm{N})$, Reasoning (PMA-R), and Word Fluency (PMA-WF).
Dickman's Impulsivity Inventory (DII; Dickman, 1990). The psychometric measure of impulsivity that we used was Dickman's Impulsivity Inventory. The Spanish adaptation of Dickman's inventory contained the 23 original items proposed by Dickman. The inventory consists of 11 items designed to measure Functional Impulsivity (FUNC) and 12 designed to measure Dysfunctional Impulsivity (DYSF) . Dickman reported an internal consistency coefficient of .74 and .85 for the functional and dysfunctional scales, respectively.

Barratt's Impulsivity Scale (BIS-10; Barratt, 1985). We also administered the Spanish adaptation of Barratt's Impulsivity Scale. This inventory contains 34 items that measure three components of impulsiveness: Motor Impulsiveness (Imp-m), Cognitive Impulsiveness (Imp-c), and Non-Planning Impulsiveness (Imp-np), which correspond to acting without thinking, making quick cognitive decisions on the spur of the moment, and "present orientation" or lack of "futuring," respectively (Patton, 1995). Barratt reported internal consistency coefficients between .89 and .92 for the BIS-10.

\section{Procedure}

The participants were recruited from the state schools in Montblanch and Tarragona, and their anonymity was guaranteed. The tests were administered collectively to groups of 40 participants and the order of administration was counterbalanced. All the inventories that had items with no response to an item or more than one response to the same item were rejected. Information about the number of failed school subjects was provided by the teaching staff.

\section{Results}

Table 1 shows descriptive statistics for all the measures in the study. The variances for intelligence measures were very close to the variances usually obtained, which assured the absence of rank restriction. The means for impulsiveness tests were also similar to the ones obtained in previous studies.

Table 2 shows the Pearson correlation coefficients between impulsivity measures. As can be seen, there is a strong relationship between dysfunctional impulsivity and the BIS-10, whereas functional impulsivity shows moderateto-low relationships with the other impulsivity measures.

Table 3 shows the Pearson correlation coefficients between impulsivity measures, and intelligence and academic failure measures. In general terms, there is a moderate negative relationship between impulsivity and intelligence measures, ranging from 0 to -0.32 . This relationship is mainly concentrated in the PMA scales, which have higher loadings in Gc (Verbal, Numerical and Word-Fluency), and is almost inexistent in the more Gf-loaded scales (Spatial and Reasoning). Moreover, the relationships are highest for scales with a verbal component. Another interesting result 
Table 1

Means and Standard Deviations Obtained in the Scales Employed

\begin{tabular}{lccr}
\hline Scale & Variable & $M$ & $S D$ \\
\hline Thurstone's Primary Mental Abilities & PMA-V & 22.98 & 19.16 \\
& PMA-S & 14.36 & 7.41 \\
& PMA-R & 6.99 \\
& PMA-N & 13.18 & 6.97 \\
& PMA-Wf & 38.51 & 10.61 \\
Dickman's Impulsivity Inventory & FUNC & 4.93 & 2.01 \\
& DYSF & 4.55 & 2.52 \\
Barratt's Impulsivity Scale & IMP-np & 24.97 & 5.28 \\
& IMP-m & 24.10 & 5.08 \\
& IMP-c & 25.74 & 3.51 \\
\cline { 2 - 4 } & BIS-10 Total & 74.81 & 2.03 \\
\end{tabular}

Note. PMA-V = Verbal, PMA-S = Spatial, PMA-R = Reasoning, PMA-N = Numerical, and PMA-Wf = Word Fluency subscales. FUNC $=$ Functional Impulsivity, DYSF $=$ Dysfunctional Impulsivity. IMP-m = Motor Impulsiveness, Imp-c = Cognitive Impulsiveness, and Imp-np = Non-Planning Impulsiveness.

Table 2

Pearson's Correlations between Impulsivity Measures

\begin{tabular}{lcccccc}
\hline & IMP-np & IMP-m & IMP-c & BIS-10 Total & FUNC & DYSF \\
\hline IMP-np & - & $.31^{* *}$ & $.40^{* *}$ & $.76^{* *}$ & $.16^{* *}$ & $.44^{* *}$ \\
IMP-m & & - & $.53^{* *}$ & $.79^{* * *}$ & $.45^{* *}$ \\
IMP-c & & - & $.77^{* *}$ & $.26^{* *}$ & $.51^{* *}$ \\
BIS-10 Total & & & - & $.29^{* *}$ & $.59^{* *}$ \\
FUNC & & & & $-15^{*}$ \\
DYSF & & & & -
\end{tabular}

Note. IMP-np = Non-Planning Impulsiveness, Imp-m = Motor Impulsiveness, and Imp-c = Cognitive Impulsiveness from Barratt's Impulsivity Scale. BIS-10 = Barrett's Impulsivity Scale. FUNC = Functional Impulsivity, DYSF = Dysfunctional Impulsivity from Dickman's Impulsivity Inventory.

$* p<.05 . * * p<.01$.

Table 3

Pearson's Correlations between Intelligence, Impulsivity, and Academic Failure

\begin{tabular}{|c|c|c|c|c|c|c|}
\hline \multirow{2}{*}{ Impulsivity Measures } & \multicolumn{5}{|c|}{ Intelligence Measures } & \multirow{2}{*}{ Academic Faillure } \\
\hline & PMA-S & PMA-V & PMA-R & PMA-N & PMA-Wf & \\
\hline IMP-np & -.02 & $-.23 * *$ & $-.15^{*}$ & $-.17 * *$ & $-.32 * *$ & $.29 * *$ \\
\hline IMP-m & .07 & .01 & -.01 & .03 & .02 & $.16^{*}$ \\
\hline IMP-c & -.02 & $-.18 * *$ & -.10 & -.09 & -.09 & $.27 * *$ \\
\hline BIS-10 Total & .02 & $-.17 * *$ & -.11 & .01 & $.18^{* *}$ & $.31 * *$ \\
\hline FUNC & .06 & .04 & .06 & .01 & -.07 & -.04 \\
\hline DYSF & .02 & $-.13^{*}$ & -.09 & $-.18 * *$ & $-.15^{*}$ & $.23 * *$ \\
\hline
\end{tabular}

Note. PMA-S = Spatial, PMA-V = Verbal, PMA-R = Reasoning, PMA-N = Numerical, and PMA-Wf = Word fluency subscales from Thurstone's Primary Mental Abilities Test. Imp-np = Non-Planning Impulsiveness, IMP-m = Motor Impulsiveness, and Imp-c = Cognitive Impulsiveness from Barratt's Impulsivity Scale. FUNC = Functional Impulsivity, DYSF = Dysfunctional Impulsivity from Dickman's Impulsivity Inventory.

$* p<.05 . * * p<.01$. 
is that the relationship between impulsivity and intelligence was highest for the non-planning scale of BIS-10, whereas the motor scale and functional impulsivity showed no significant relationship.

As far as academic failure is concerned, all the impulsivity scales, with the exception of functional impulsivity, showed a moderate relationship with the number of failed subjects. This indicates a possible relationship between impulsivity and academic failure.

\section{Discussion}

The above results are consistent with the usual findings in the domain of personality-intelligence relationships. Impulsivity shows a moderate relationship with psychometric measures of intelligence, and is more specific to crystallized intelligence measures. Nevertheless, the possible causes of this relationship are important. Although most of the impulsivity measures showed significant relationships with intelligence, the pattern of correlations between them indicates that the absence of planning (Imp-np) and the tendency to take quick decisions without forethought (Impc) - two variables that characterize impulsive individualsmay be responsible for the negative relationship observed between impulsivity and intelligence. This problem-solving style based on quick decisions without taking into account the consequences may also lead to learning problems that are reflected in both scores on crystallized intelligence measures and academic achievement. From this viewpoint, impulsivity may act as a variable that moderates the way in which individuals use their resources within the framework of the investment theory. Nevertheless, further research including measures of learning performance is needed to confirm the role of impulsivity in this relationship.

In addition, impulsivity shows greater relationships with verbal performance scales (the PMA Verbal and WordFluency scales). A similar result was also reported by Lynam and colleagues (1993), who found that impulsivity was more related to verbal IQ than to performance IQ, which may indicate dysfunctions at an executive level that interfere with self-control.

A second possible explanation is the strategies that impulsive individuals use when they respond to intelligence tests. In this respect, Phillips and Rabbitt (1995) reported that impulsive individuals tend to use strategies based on speed in intelligence tests, which may lead to poorer performance in some cases. Nevertheless, if the relationships between impulsivity and intelligence were due to inadequate strategies, we should expect to find this effect for both Gc and Gf measures of intelligence and not only for scales with high loadings on Gc. As a result, the explanation that the impulsivity-intelligence relationship is based on response strategies seems inappropriate because we have found no pattern of negative impulsivity correlations with all the PMA scales.
As far as the relationships between functional impulsivity and intelligence are concerned, the present study did not uphold the hypothesis that functional impulsivity is related to intelligence because of speed of processing. This is along the lines of the proposals made by Rindermann and Neubauer (2001) and Bates and Rock (2004), in the sense that personality and processing speed have independent influences on intelligence. Moreover, intelligence has often been related to initial and decision stages of information processing, whereas impulsivity has been related to response execution stages (Brand, 1984; Brand \& Deary, 1982; Expósito \& Andrés-Pueyo, 1997).

Further research is needed to clarify the causes of impulsivity-intelligence relationships and to account for the possible interferences of impulsivity in learning processes. This approach may help us to understand whether impulsivity is directly related to intelligence or whether it acts as a moderator variable between individuals' resources and their achievements.

\section{References}

Ackerman, P.L. (1994). Intelligence, attention and learning: Maximal and typical performance. In D.K. Detterman (Ed.), Current topics in human intelligence. Vol. 4: Theories of intelligence (pp. 1-27). Norwood, NJ: Ablex.

Ackerman, P.L., \& Heggestad, E.D. (1997). Intelligence, personality and interests: Evidence for overlapping traits. Psychological Bulletin, 121, 219-245.

Ashton, M.C., Lee, K., Vernon, P.A., \& Lang, K.L. (2000). Fluid intelligence, crystallized intelligence, and the openness/intellect factor. Journal of Research in Personality, 34, 198-207.

Austin, E.J., Deary, I.J., \& Gibson, G.J. (1997). Relationships between ability and personality: Three hypotheses tested. Intelligence, 25, 49-70.

Barratt, E.S. (1985). Impulsiveness subtraits: Arousal and information processing. In J.T. Spence \& C.E. Itard (Eds.), Motivation, emotion and personality (pp. 137-146). Amsterdam: Elsevier. (Spanish adaptation: Luengo, Carrillo-de-la-Peña, \& Otero, 1991.)

Bates, T.C., \& Shieles, A. (2003). Crystallized intelligence as a product of speed and drive for experience: The relationships of inspection time and openness to Gc. Intelligence, 31, 275-287.

Bates, T.C., \& Rock, A. (2004). Personality and information processing speed: Independent influences on intelligent performance. Intelligence, 32, 33-46.

Brand, C.R. (1984). Intelligence and inspection time: An ontogenetic relationship? In C.H. Turner (Ed.), The biology of human intelligence (pp. 53-64). North Humberside, UK: Natterton.

Brand, C.R., \& Deary, I.J. (1982). Intelligence and inspection time. In H.J. Eysenck (Ed.), A model for intelligence (pp. 133-148). New York: Springer-Verlag.

Brebner, J., \& Stough, C. (1995). Theoretical and empirical relationships between personality and intelligence. In D.H. 
Saklofske \& M. Zeidner (Eds.), International handbook of personality and intelligence (pp. 321-348). New York: Plenum Press.

Brunas-Wagstaff, J., Bergquist, A., \& Wagstaff, G.F. (1994). Cognitive correlates of functional and dysfunctional impulsivity. Personality and Individual Differences, 17, 289-292.

Chico, E., Tous, J.M., Lorenzo-Seva U., \& Vigil-Colet A. (2003). Spanish adaptation of Dickman's Impulsivity Inventory, its relationship to Eysenck's Personality Questionnaire. Personality and Individual Differences, 35, 1883-1892.

Claes, L., Vertommen, H., \& Braspenning, N. (2000). Psychometric properties of the Dickman Impulsivity Inventory. Personality and Individual Differences. 29, 27-36.

Demetriou, A., Kyriakides, L., \& Avraamidou, C. (2003). The missing link in the relations between intelligence and personality. Journal of Research in Personality, 37, 547581.

Dickman, S.J. (1990). Functional and dysfunctional impulsivity: Personality and cognitive correlates. Journal of Personality and Social Personality, 58, 95-102.

Dickman, S.J. (1993). Impulsivity and information processing. In W. McCown, M. Shure., \& J. Johnson (Eds.), The impulsive client: Theory, research and treatment (pp. 151-184). Washington, DC: American Psychological Association.

Dickman, S.J. (2000). Impulsivity, arousal and attention. Personality and Individual Differences, 28, 563-581.

Eysenck, H.J. (1987). Speed of information processing, RT, and the theory of intelligence (pp. 57-85). In P.A. Vernon (Ed.), Intelligence and speed of information processing. New York: Ablex.

Eysenck, H.J. (1994). Personality and intelligence: Psychometric and experimental approaches. In R.J. Sternberg \& P. Ruzgis (Eds.), Personality and intelligence (pp. 3-31). New York: Cambridge University Press.

Expósito, J., \& Andrés-Pueyo, A. (1997). The effects of impulsivity on the perceptual and decision stages in a choice reaction time task. Personality and Individual Differences, 22, 693-697.

Fink, A.D., \& McCown, W.G. (1993). Impulsivity in children and adolescents: Measurement, causes and treatment. In W. McCown, M. Shure., \& J. Johnson (Eds.), The impulsive client, theory, research and treatment (pp. 279-308). Washington, DC: American Psychological Association.

Furnham, A., Forde, L., \& Cotter, T. (1988). Personality and intelligence. Personality and Individual Differences, 24, 187192.

Goff, M., \& Ackermann, P.L. (1992). Personality-intelligence relations: Assessment of typical intellectual engagement. Journal of Educational Psychology, 84, 537-552.
Helmers, K.F., Young, S.N., \& Pihl, R.O. (1995). Assessment of measures of impulsivity in healthy male volunteers. Personality and Individual Differences, 19, 927-935.

Jensen, A.R. (1981). Bias in mental testing. London. Methunen.

Jensen, A.R. (1993). Why is reaction time correlated with psychometric g? Current Directions in Psychological Science, 2, 53-56.

Jensen, A.R. (1998). The $g$ factor. London: Praeger.

Luengo, M.A, Carrillo-de-la-Peña, M.T, \& Otero, J.M. (1991). The components of impulsiveness: A comparison of the I7 Impulsiveness Questionnaire and the Barratt Impulsiveness Scale. Personality and Individual Differences, 12, 657-667.

Lynam, D., Moffitt, T., \& Stouthamer-Loeber, M. (1993). Explaining the relation between IQ and delinquency: Class, race, test motivation, school failure or self-control? Journal of Abnormal Psychology, 2, 187-196.

McMurran, M., Blair, M., \& Egan, V. (2002). An investigation of the correlations between aggression, impulsiveness, social problem-solving, and alcohol use. Aggressive Behavior, 28, 439-445.

Messer, S.B. (1976). Reflection-impulsivity: A review. Psychological Bulletin, 83, 1026-1052.

Patton, J.H. (1995). Factor structure of the Barratt Impulsiveness Scale. Journal of Clinical Psychology, 51, 768-774.

Phillips, L.H., \& Rabbitt, P.M.A. (1995). Impulsivity and speedaccuracy strategies in intelligence test performance. Intelligence, 21, 13-29.

Rindermann, H., \& Neubauer, A. (2001). The influence of personality on three aspects of cognitive performance: Processing speed, intelligence and school performance. Personality and Individual Differences, 30, 829-842.

Schweizer, K. (2002). Does impulsivity influence performance in reasoning? Personality and Individual Differences, 33, 1031-1043.

Thurstone, L. L. (1938). Primary mental abilities. Chicago: Univeristy of Chicago Press. (Spanish adaptation: Aptitudes mentales primarias. Madrid: TEA, 1989).

Weijers, H.G., Wiesbeck, G.A., \& Böning, J. (2001). Reflectionimpulsivity, personality and performance: A psychometric and validity study of the Matching Familiar Figures Test in detoxified alcoholics. Personality and Individual Differences, 31, 731-754.

Zeidner, M. (1995). Personality trait correlates of intelligence. In D.H. Saklofske \& M. Zeidner (Eds.), International handbook of personality and intelligence (pp. 299-320). New York: Plenum Press.

Received February 9, 2005

Review Received May 2, 2005 Accepted May 6, 2005 